Journal of Teacher Education for Sustainability, vol. 17, no. 1, pp. 72-85, 2015

\title{
Environmental Education in Pre-Service Teacher Training: A Literature Review of Existing Evidence
}

\author{
Olaya Álvarez-García, Jaume Sureda-Negre and Rubén Comas-Forgas \\ University of the Balearic Islands, Spain
}

\begin{abstract}
The importance of pre-service teacher training regarding environmental education (EE) has been vastly demonstrated. This systematic review examined the existing evidence from studies evaluating and analysing the relationship between EE, including environmental competences and pre-service primary school teacher training. The literature review performed included 24 documents $(22$ peer reviewed journal articles and two doctoral theses). The strategy followed consisted in locating documents by a reliable search strategy; establishing the criteria for the selection of documents to analyse from the documents located and rigorously analysing the documents selected based on clear and precise criteria and dimensions. In general terms, the literature review analysis has emphasised the lack of environmental competences amongst pre-service teacher students and the gaps in the teacher training curriculums regarding EE. The overall scarcity of research in this area, jointly with certain gaps and methodological limitations, affirms the need for strengthening the evidence base.
\end{abstract}

Keywords: environmental education, pre-service teacher training, education for sustainable development, environmental competencies, literature review

Teacher training, whether pre-service or continuous professional development, is an essential element to introduce environmental education (EE) in schools. The need for and relevance of this training was already made explicit in the major EE conferences held by the United Nations Educational, Scientific and Cultural Organisation (UNESCO) in the 1970s and 1980s (UNESCO, 1975, 1977, 1987). As a result of this interest and of the international consensus arising from it, UNESCO published a set of experimental modules on pre-service and continuous teacher training throughout the 1980s and 1990s, some examples of which are the works of Fensham, Hunwick and Jacobson (1986), Marcinkowski, Volk and Hungerford (1990), Sinha, Jangira and Das (1985), Wilke, Peyton and Hungerford (1987).

In 1990, UNESCO/UNEP identified this training as the 'priority of priorities' for improving EE. Along the same lines and in the same decade, other conferences and international agreements on the issue once again highlighted the need to reorient teacher 
training in order to promote sustainability (UNESCO, 1997; United Nations (UN), 1992). In 1999, UNESCO created the UNITWIN/UNESCO Chair for Reorienting Teacher Education to Address Sustainability, whose goal was to take leadership in developing an international pilot network among existing teacher training institutions and facilitate and coordinate its work (UNESCO, 1999). Emanating from the UNESCO World Conference on Education for Sustainable Development (2009), what became known as the Bonn Declaration (UNESCO, 2009), called for efforts to be directed to reorient curriculum and teacher education programmes to integrate ESD into both preservice and in-service programmes.

Numerous documents have analysed the situation of EE over the years and shown the need for teacher training in this field. In France, for example, a report commissioned by several ministries to develop a future strategy for sustainability notes that ESD cannot be carried out effectively without supporting teacher training efforts (Bregeon, Faucheux, \& Rochet, 2008). Similarly, an earlier report suggests that teacher training is a necessary requirement for successful education in this area (Bonhoure \& Hagnerelle, 2003). Furthermore, the need for this type of training is highlighted in some research conducted within higher education. The incorporation of ESD into the curricula of preservice teacher training ensures the promotion of sustainability amongst future citizens. This education could be promoted through the teaching of science (Madhawa Nair, Rashid Mohamed, \& Marimuthu, 2013), scientific experimentation (Karpudewan, Ismail, \& Mohamed, 2009) and initiatives (Henze, 2000) related to Agenda 21 (UN, 1992). However, a case study conducted in five faculties of education in Manitoba Canada noted that, despite the relevant efforts made for the integration of this education into pre-service teacher education institutions, ESD has been poorly incorporated into the curriculum (Falkenberg \& Babiuk, 2014). This context, or lack of, invites us to wonder about the state of the art in pre-service teacher training regarding EE. It is important to be acquainted with the evidence and the existing body of knowledge in this area, not only for the construction of cumulative scientific knowledge, but also to support opening new areas of inquiry.

\section{Objectives}

The aim of this study is to undertake a review of published scientific literature on pre-service primary teacher training (PsPTT) regarding EE. This involves locating, classifying and analysing research conducted on the topic. This study concentrates on describing peer-reviewed journal articles and dissertations on the topic, and answers the following questions:

- What are the main topics discussed on PsPTT regarding EE?

- What are the main outcomes, evidences and findings of the works analysed?

- What are the implications of the outcomes and conclusions of the works analysed?

\section{Meta-Analysis Procedure}

For a systematic review of the documents, a number of stages were followed that can roughly be summarised into the following three: locating documents by the use of a consistent search strategy; establishing the criteria for the selection of documents to be 
considered from the set of documents found and, finally, analysing these rigorously selected documents based on clear and precise criteria and dimensions (Higgins \& Green, 2011).

The peer-reviewed journal articles were located by consulting major scientific databases: ERIC, Web of Science, SCOPUS, REDINED and Dialnet (Spanish databases). Doctoral theses were located by the use of three databases: ProQuest Dissertations \& Theses Database (PQDT), Dart-Europe and Tesis Doctorales en Red (TDX). Although the authors are aware of the existence of other types of documents that could also have been analysed (research reports, books and book chapters, conference proceedings, etc.), the review was limited to academic papers published in peer-reviewed journals and doctoral theses, as both have been subject to rigorous review and are, therefore, high-quality documents.

The search strategy was based on systematically organising, categorising and selecting keywords related to EE and pre-service teacher training. To do this, a word search was conducted in the ERIC thesaurus, in English, in relation to the terms training, EE, education for sustainable development (ESD), primary teachers, pre-service teacher training and university. Using these keywords, a common search strategy was developed for the various databases consulted, adapting it to the characteristics of the given platform. For each database, a hierarchical search strategy was applied, starting from the most complex form to the simplest expression, with the aim of retrieving documents from all databases. Depending on the requirements of each database, the search fields were basically limited to the title and abstract of the documents, with consideration of all those published until 2014. In each database, various refined search strategies were employed for consistency purposes, such as solely locating peer reviewed papers in ERIC or only selecting papers in Web of Science, for example.

After obtaining the document records, those to be analysed were identified. The following criteria were used for the screening process:

a) eliminating the records of documents that do not specifically refer to EE in PsPTT;

b) eliminating duplicate records;

c) eliminating those documents that could not be accessed.

Regarding content, the concepts used and the main issues involved in the relationship of PsPTT with EE/ESD were analysed, together with the main results and conclusions. Those paragraphs referring to EE in PsPTT were selected from the documents to determine the units for analysis.

In order to ensure the reliability of the process, the three members of the research team conducted the selection of information units, the categorisation and subsequent analysis independently. Fieldwork associated with locating of documentation, was performed during October, November and December 2014; the processing, analysis and data mining took place during January and February 2015.

\section{Results}

From the content analysis, the documents can be broadly categorised along four areas:

a) analysis of the research on EE in PsPTT;

b) analysis of the research on training experiences in EE and ESD; 
c) proposals for models of EE in PsPTT;

d) integration of EE/ESD into the curriculums of PsPTT qualifications.

\section{Evaluation of EE in PsPTT}

Nine studies were included in this category, which evaluated EE in pre-service teacher training by analysing several variables. Miles, Harrison and Cutter-Mackenzie (2006) analysed the perceptions and experiences regarding EE of students enrolled in the second and third year of a teacher training faculty of an Australian university. This involved conducting a focus group on a sample of seven students to determine the encounters those future teachers had with EE during their training courses. From this information, the researchers designed a questionnaire to evaluate the experiences in connection with EE of a sample of 131 students, their knowledge of the discipline and where this knowledge had been obtained and their views on their preparation for EE teaching. This survey data shows that $50.3 \%$ of students indicated that most of their relationship with EE had occurred during classes and rarely in their school practices $(28.9 \%)$. Likewise, the assessment that the students themselves performed on the teaching of EE, measured on a scale from 1 (low) to 5 (high), suggested that students were reasonably interested in the teaching of EE (average of 3.3), but that their knowledge of $\mathrm{EE}$ and their preparation to teach it was inadequate (average values of 2.5 and 2.3, respectively). According to these results, the authors concluded that "there are still inadequate levels of EE provision at the teacher education level and pre-service primary teachers' preparedness for teaching EE is overwhelmingly low" (Miles, Harrison, \& Cutter-Mackenzie, 2006, p. 57).

To determine the level of environmental competences acquired by pre-service teachers, the following characteristics were analysed in several studies: their knowledge, attitudes and their environmental behaviour and their environmental literacy. Examples of the first category include the works carried out by Boon (2010), Puk and Stibbards (2010), Tal (2010). In Boon (2010), the knowledge about climate change was evaluated by using a sample of pre-service primary, secondary and early childhood teachers in the final year of their degree programme $(n=107)$. Of this sample, 56 participants were future primary school teachers. The administered questionnaire examined their knowledge and ideas about the greenhouse effect and the ozone layer hole, the sources from which they had obtained this knowledge and the actions that they were willing to take to mitigate their environmental footprint. The results were compared with a sample of 310 secondary school students. No significant differences were found between students and pre-service teachers regarding aspects such as understanding the greenhouse effect and the function of the ozone layer. The future teachers only seemed to be better informed about these phenomena because they had a greater interest in gathering information through the media. The study conducted by Boon (2010) highlighted the need to develop curricula to overcome gaps in knowledge and the understanding of the specific items in the school curriculum and the need to include them in the training of teachers. Meanwhile, Tal (2010) utilised a questionnaire on environmental issues at the beginning and end of an introductory course in EE for pre-service teachers at a university in Israel. The questionnaire aimed to assess participants' knowledge of environmental issues and their reflections on the course itself. The environmental knowledge of the 75 students surveyed was very poor at the beginning of the course, but had improved by the end of it. In 
relation to the opinions expressed about the course itself, the students indicated that the course had provided them with new knowledge about environmental matters, improved their environmental awareness and allowed them to discover new teaching methods for their practice. Consequently, it was suggested that courses on environmental issues should be introduced in teacher training curricula in order to overcome the low level of environmental knowledge and improve environmental literacy. Finally, Puk and Stibbards (2010) analysed the definitions of several concepts used to evaluate the ecological knowledge of 15 pre-service teachers in Ontario, Canada. The results revealed a lack of understanding of core concepts about how natural systems work and the impact of social systems on natural systems; however, these concepts were considered essential for the training of future teachers and their ecological literacy. It was concluded that it is necessary to incorporate specific training on ecological literacy into PsPTT programmes.

The results of the three studies described a low level of environmental knowledge of pre-service teachers and highlighted the need for EE training for these future educators by including this discipline in pre-service teacher training qualifications. However, despite this limited knowledge, some research suggests that student teachers have positive attitudes towards EE. Kyridis, Mavrikaki, Tsakiridou, Daikopoulos and Zigouri (2005) administered a questionnaire that assessed attitudes towards EE of 76 primary school student teachers and 96 kindergarten student teachers after completion of a six-month EE course. The dimensions of analysis covered: the methodology used in EE; the role of $\mathrm{EE}$ in the curriculum; objectives and issues addressed by EE and the relationship between students and EE. The analysis of the data revealed that most participants had positive attitudes towards $\mathrm{EE}$ in their role as students, although their attitudes were more negative when compared to their future role as teachers. Likewise, students believed that EE would help them to become acquainted with more innovative teaching methods and to improve teacher-student relationships. In conclusion, the authors emphasised that the major responsibility of the university is to promote interest in environmental issues among their students in order to enable them to not only look for solutions to environmental problems, but also to be professional promoters of sustainability.

Goldman, Yavetz and Pe'er (2006) conducted a longitudinal study among student teachers in three universities and teacher training centres in Israel at the beginning and end of their studies to assess their level of environmental literacy. In the first study, the sample consisted of 765 new students at the beginning of their degree programme. The instrument used was a questionnaire that analysed environmental knowledge, attitudes and behaviour. The environmental behaviour scale consisted of 20 items with environment-related activities, in which respondents were asked to rate the frequency they carried out those activities, using a five-point Likert scale $(1=$ never to $5=$ almost always). The results showed a low level of environmentally responsible behaviour of students (total mean value of 3.19), which may be related to a low level of environmental literacy. In addition, there were significant differences between students of the areas of sciences and social sciences, with the former showing better environmental behaviour. Subsequent studies (Goldman, Yavetz and Pe'er, 2014) compared the differences in environmental literacy between these same students by considering a sample of 214 students in relation to the area of specialisation that they studied: environmental or non-environmental. Results confirmed that there were significant differences between the two groups in certain aspects and in some characteristics of their environmental behaviour and basic environmental knowledge. The authors recommended including at least one specific EE 
course in the degree programme for non-environmental specialists or including it as a component of a subject. When they analysed the understanding of the concept of environment among the participants, they found that students recognised that EE was important for their future teaching role, but these participants did not demonstrate an adequate understanding of the concept of environment. Consequently, the authors state that "all student teachers should receive appropriate preparation in this field... EE [should] not be limited to science disciplines; rather it should be included in all teacher education programs" (Yavetz, Goldman, \& Pe'er, 2014, p. 370). Also, in this line of inquiry, a study conducted in Turkey (Tuncer, Boone, Tuzun, \& Oztekin, 2014) applied a specific method to measure the environmental literacy of pre-service student teachers in four universities in Ankara. The questionnaire was administered to a sample of 2,311 students and consisted of four components of environmental literacy: knowledge, attitudes, attitudes towards environmental responsibility and concern. The authors concluded that students were concerned about the issues that affect their personal lives in the short term, but were not able to establish relationships between environmental problems and factors, such as their level of consumption, because of their low EE knowledge. The analysis of the different variables led these authors to claim that future teachers have a low level of environmental literacy.

As a summary of this section, we can point out that research carried out suggests that prospective teachers acquire low levels of environmental competences and basic environmental knowledge during their higher education training, although they tend to have positive attitude towards EE and ESD.

\section{Evaluation of Training Experiences in EE and ESD}

A total of nine studies focused on analysing the effectiveness of models, programmes, courses and methodologies implemented in order to train future primary teachers in teaching EE/ESD. These are a series of empirical studies centred on specific experiences that seek to improve the knowledge and teaching methodologies in EE among preservice teachers.

In 1976, Bluhm and Hungerford applied a model to introduce EE and the concepts of ecology to all pre-service elementary teacher students at the University of Southern Illinois, USA. To assess the conception of EE, the definition of EE held by the students was quantitatively assessed; to assess the notions of ecology, a 17-item multiple-choice and short-answer questionnaire was developed regarding some ecological concepts. The instrument was administered at the beginning and end of the course to a sample of 44 students in the experimental group and 16 students in the control group. The results indicated that the model applied significantly influenced the perception of EE. Likewise, the application of the model allowed the concepts of ecology to be acquired in a short period of time. In a model subsequently developed (Gayford, 2004) for pre-service teachers in relation to education for sustainability, the inclusion of EE in the science curriculum of future primary teachers was planned and evaluated. Pre-service teachers who applied this model to their practice considered that, in general terms, it was a successful model that had allowed them to see how they could contribute to this area of education through their specialisation. The model proposed by Summers, Childs and Corney (2005) is also worth noting in connection with ESD. These authors proposed integrating ESD in schools by adopting an interdisciplinary approach into the subjects 
of the pre-service primary teachers' curriculum. To do this, they evaluated the way in which this education was implemented by administering questionnaires to geography and science student teachers, their tutors in schools and the principals of the schools in which teaching practice was held. The analysis of results showed that the schools were not prepared as a learning context to address sustainability from an interdisciplinary viewpoint, and that the understanding of sustainability by both student teachers and their mentors was not pertinent for its application in the classroom.

PsPTT on environmental issues has also been conducted through specific courses and methodologies, which have shown positive results among future teachers. A case study analysed the training received by a group of student under the umbrella of environment and school initiatives (Varga, Kószó, Mayer, \& Sleurs, 2007). Participants were evaluated as they followed a process for the introduction of ESD in the classroom during their teaching practice. Results showed the feasibility of the experience of improving skills in sustainability among these teachers. Van Petegem, Blieck and Pauw (2007) evaluated the implementation process of EE in two Flemish teacher education colleges: one college had a long history of integrating EE into its training programme, while the other did not. To analyse the results of the experience, the views of the teaching faculty responsible for the implementation of EE in the degree and the opinions of the students about the training were evaluated. It was noted that, despite the fact that specific courses in EE were integrated into the curriculum for pre-service teacher education of both universities, environmental issues were usually presented in specialist science courses, namely biology and earth sciences. For students trained in EE, the courses were a good curricular tool and allowed them to work in an interdisciplinary way, but their environmental awareness and environmental responsibility diminished rapidly after the courses, which makes clear the need for on-going EE training. No major differences were observed in the results of the two institutions regarding their background in the implementation of EE, as the implementation process was problematic in both cases due to the teaching faculties' lack of EE training skills, their difficulty in engaging in teamwork and the differences between the different areas of education.

The method implemented by Kilinē (2010) sought to encourage pro-environmental behaviour among pre-service primary student teachers in a Turkish university. 33 students in the sample took an Environmental Sciences module in which they applied a working methodology that involved undertaking different action research projects in relation to some environmental topics and didactic methods used. The effectiveness of the method was evaluated by using both qualitative and quantitative techniques by administering a questionnaire at the beginning and at the end of the courses. Data showed that the environmental behaviour of students improved after the course; the average values of their behaviour ranged from 3.76 to 6.27 , measured on a scale of 1 to 8 . Improvements were also noted in the environmental behaviour of students after carrying out some environmental projects. Based on the results of this study, authors suggested that this methodology should be applied in PsPTT in order to change students' beliefs about EE and encourage them to behave more pro-environmentally and serve as an example to their future students.

The doctoral thesis of Cardona (2012) is another example of an EE training experience. The research was conducted amongst undergraduate science students of primary education from the University of Antioquia, Colombia, who were still in PsPTT but were already working in primary schools. Data were collected through questionnaires, 
written documents and interviews with 12 participating teachers and analysed qualitatively. From the results, it was suggested that student teachers lacked sufficient knowledge and skills to build proposals for EE in the classroom and that this was a gap in their training.

The studies conducted in two Swedish universities by Andersson, Jagers, Lindskog and Martinsson (2013) were identified as examples of ESD training. These consisted in evaluating the effects of an ESD course on student teachers. The comparative study examined the beliefs, attitudes and moral obligations towards sustainability by the use of a questionnaire that was administered at the beginning and end of an ESD module. The sample included a control group composed by 97 students that did not follow the module and an experimental group of 323 students who were taking the ESD course. Changes in beliefs and moral standards were measured by the use of a Likert scale, which showed increased positive averages for the experimental group in most measured beliefs, while no effects were observed in the control group of students. The study also assessed whether teachers who had shown a greater interest in environmental issues at the start of the study had experienced greater changes, with no significant differences being observed. The authors concluded that participation in this course by student teachers could help to promote sustainability among future educators.

The experiences in Spain include the study carried out on the Primary Education Teaching Degree at the University of Girona (Junyent, 2002). This doctoral thesis analysed the impact of a cooperative work methodology applied to one EE module. Qualitative techniques were used to analyse the reflections of the 42 pre-service teachers participating in the study. The analysis of the data showed that the methodology had positive effects on student teachers to incorporate environmental considerations into their teaching (Junyent, 2002).

Summarising this section, we can indicate that there is a lack of environmental competences amongst the future teacher's trainers at the universities and higher education institutions, and that the most appropriate methodologies to work EE and ESD amongst PsPTT students are based on collaborative, interdisciplinary and experiential activities.

\section{Proposals of Models for The Training of Teachers in EE/ESD}

In four of the studies analysed, programmes for PsPTT in EE/ESD were described and evaluated. Since the 1980 s an obvious need has been identified to orient training in this area through models that would improve the ability of teachers to educate socially and environmentally responsible citizens. Some models, such as that proposed by Caduto (1985), indicated that student teachers should be trained to implement an education that promotes what he describes as environmental values. This could be gained through (i) philosophical values; (ii) values of nature and social dynamics; (iii) methodologies for implementing this kind of values education based on moral development, analytical skills, active learning, changes in behaviour, etc.; (iv) communication skills and (v) knowledge of the nature of environmental values education in the context of formal and informal education institutions. A similar model was proposed by Wilke (1985) based on an experiment conducted at the University of Wisconsin, United States. According to the author, teachers must acquire some environmental competencies, and, subsequently, EE training is a requirement for the successful completion of the degree. These competencies include that student teachers should be able to (i) apply the knowledge of 
the philosophy of education in the curricula to be developed, as well as in the strategies used, to achieve the general objectives of education and EE; (ii) use existing theories linking knowledge, attitudes and behaviour for the selection, development and implementation of a curriculum that maximises the probability of causing behavioural changes in the students; (iii) teach students about the transfer of learning to ensure that the promoted skills are included in the daily lives of students. In a later piece of research, Stone (1989) reaffirmed the guiding strategies of UNESCO (Wilke, Peyton, \& Hungerford, 1987) on the EE competencies that teachers should acquire in order to act appropriately and effectively in the classroom. These competencies refer to the knowledge and the ability to implement EE in the school curriculum and the knowledge about ecology and environmental issues that teachers should possess. In order for EE to be infused into schools, the author argued that this discipline should be implemented in teacher education programmes and should be performed through a cross-disciplinary approach, that is, across all of the subjects in the curriculum.

Finally, as a model descriptor, Alvarez and Vega (2004) noted, in connection with PsPTT, that "the profile of the EE teacher should contain the following features: a) the ability to adapt their subject or area of knowledge to the interpretation of real environmental facts; b) closeness to and respect for the environment, considering it in its entirety and integrating into it the whole gamut of human activities; c) the ability to make a realistic reading of the events which have an environmental impact and know-how to transform this into an educational project; d) the awareness of being a depository and producer of ethical codes with which to address environmental challenges" (p. 68).

Regarding this specific section, it is important to note that research points out the necessity of implementing training models that cover both environmental competencies of future teachers and also gives them a sufficient pedagogical background to transform these competences in teaching skills and capacity in their future role of teachers.

\section{Evaluation of the Integration of EE/ESD into the Curriculums of University Teacher Training Courses}

Two studies were found that analysed the integration of EE into the university curricula of primary PsPTT courses. A case study from the University of La Laguna, in the Canary Islands, analysed the importance given to EE in the curricula of primary, early childhood and pedagogy courses at this university and its presence in educational projects of the individual teaching subjects. The analysis showed that EE as a subject was present in only one specialty; otherwise, it was treated as content in different subjects. The ecological concept prevailed, and it was noted that there was little presence of EE in educational projects (Suárez \& Teixé, 2007). A later study (Sureda, Oliver, Catalan, \& Comas, 2014) carried out an in-depth analysis of the situation in different Spanish universities after the process of convergence emerged from the European higher education area. These authors analysed the inclusion of environmental competencies in the primary teacher's degree plans in 23 Spanish universities. The results highlighted the lack of specific training in EE in the curriculum of the degrees: only $26 \%$ of programmes included a specific EE subject, and it was always optional to students.

As a summary of this specific are of analysis, it is relevant to reflect that research carried out stresses the necessity of introducing EE subjects/modules in the curriculums of the prospective teachers' courses. 


\section{Discussion and Conclusions}

The documents retrieved from the literature search conducted allowed us to deepen our understanding of some formal aspects and to make a summary of the research conducted to date. However, we are aware that the results of this review are limited by the documentary sources consulted and the type of resources analysed, as it must be remembered that only articles published in peer-reviewed academic journals and doctoral theses were considered. There are undoubtedly documents of interest on this topic that were not included in the academic databases consulted and therefore have not been considered to provide a thoroughly comprehensive overview of the state of the art of EE education in PsPTT.

According to the research content, the frequency of terms used leads us to posit that while EE is one of the most frequently used terms (899), ESD (282) also has importance in the environmental training of teachers, probably due, amongst other factors, to the implementation of the Decade of Education for Sustainable Development (DESD) in 2005.

In light of the content analysis performed, we have seen the topic of EE present in discussions about teacher training since the 1970s. Although in the early years, the issues were mainly theoretical in nature, with proposals for promoting this type of training, in recent years there has been an attempt to empirically show the current state of affairs for students studying these degrees. The outcomes of this research have highlighted the low level of teacher training in EE, either because of their low environmental knowledge (Boon, 2010; Puk \& Stibbards, 2010; Tal, 2010) or their poor environmental literacy (Goldman, Yavetz, \& Pe’er, 2006; Tuncer, Boone, Tuzun \& Oztekin, 2014). Much of the research that empirically evaluated this training agreed on the need to include EE in the curricula of PsPTT. In the case of Spain, according to the latest research, it appears that the curricula are oriented in this direction (Sureda-Negre, Oliver-Trobat, Catalan-Fernández, \& Comas-Forgas, 2014).

In summary, the studies analysed point to the undeniable role of teachers in the infusion of EE into schools as a tool to environmentally educate future citizens. However, for this education to be effective in schools, adequate training of pre-service teachers is needed so that those professionals gaining these qualifications can achieve the competencies of an environmentally educated person and the professional competencies of an environmental educator (Alvarez \& Vega, 2004). Regarding the first group of competencies, the various studies that have evaluated the training of teachers in EE have shown somewhat disappointing results. As to the second group of competencies, the models proposed in the 1980s should be revised. Additionally, those experiences that have proven to be effective in improving the training of future teachers should be analysed with a view to refocusing the curricula of PsPTT qualifications towards the acquisition of these competencies.

\section{Recommendations}

Based on the literature meta-analysis carried out regarding EE in PsPTT, we feel it is necessary to:

- implement a profound review of how environmental competences are instructed amongst future teachers at the universities and how environmentally competent 
prospective teachers are when they finish their training before starting their professional career;

- establish clear minimum criteria (basically, competences, contents and teaching methodologies and didactics of EE) in the curricular design of the PsPTT, which will warrant basic preparation in EE for future primary teachers and, consequently, impact their future pupils;

- improve the relevance of the concepts and competences related to EE in the PsPTT curriculums, without falling into what Elliot expressed (1998, cited by Wong Bing Kwan \& Stimpson, 2003) as “politically symbolic acts which publicly signify concern for the environment, rather than with the construction of effective and educationally worthwhile pedagogic practices for EE" (p. 174);

- analyse and focus on which pedagogic/didactic methodologies best improve the environmental competences amongst prospective teachers during their pre-service training period at the universities and training centres;

- promote learning experiences among PsPTT students based on practical and experiential activities;

- implement specific compulsory modules on EE and ESD to prospective teachers during their pre-service training.

\section{References}

Alvarez, P., \& Vega, P. (2004). Formación inicial del profesorado en Educación Ambiental [Environmental education in pre-service teacher training]. Revista Biocenosis [Journal Biocenosis], 18(1-2), 66-71.

Andersson, K., Jagers, S. C., Lindskog, A., \& Martinsson, J. (2013). Learning for the future? Effects of education for sustainable development (ESD) on teacher education students. Sustainability, 5(12), 5135-5152. doi: 10.3390/su5125135

Bluhm, W. J., \& Hungerford, H. R. (1976). Modifying pre-service elementary school teachers' perspectives. The Journal of Environmental Education, 7(4), 14-17. doi: 10.1080/00958964. 1976.9941541

Bonhoure, G., \& Hagnerelle, M. (2003). L'education relative à l'environnement et aux développement durable: Un état des lieux, des perspectives et des propositions pour un plan d'action [Education on the environment and sustainable development: An inventory, perspectives and proposals for an action plan]. Retrieved from http://media.education.gouv.fr/file/01/2/6012.pdf

Boon, H. J. (2010). Climate change? Who knows? A comparison of secondary students and pre-service teachers. Australian Journal of Teacher Education, 35(1), 104120.

Bregeon, J., Faucheux, S., \& Rochet, C. (2008). Rapport du groupe de travail interministériel sur l'éducation au développement durable [Report of the interdepartmental working group on education for sustainable development]. Retrieved from http://cache.media.education.gouv.fr/file/2008/27/0/Strategie_pour_1_EDD_ 23270.pdf

Caduto, M. J. (1985). A teacher training model and educational guidelines for environmental values education. The Journal of Environmental Education, 16(2), 30-34. doi: 10.1080/00958964.1985. 10801950 
Cardona, J. D. (2012). Concepciones sobre educación ambiental y desarrollo profesional del profesorado de ciencias experimentales en formación [Conceptions of environmental education and professional development of pre-service science teachers] (Doctoral dissertation). Retrieved from http://rabida.uhu.es/dspace/bitstream/ handle/10272/6158/Tesis_anexos.pdf?sequence=3

Falkenberg, T., \& Babiuk, G. (2014). The status of education for sustainability in initial teacher education programmes: A Canadian case study. International Journal of Sustainability in Higher Education, 15(4), 418-430. doi: 10.1108/IJSHE-10-2012-0088

Fensham, P., Hunwick, J., \& Jacobson, W. J. (1986). Environmental education: Module for pre-service training of science teachers and supervisors for secondary schools. Retrieved from http://unesdoc.unesco.org/images/0007/000714/071480eo.pdf

Gayford, C. (2004). A model for planning and evaluation of aspects of education for sustainability for students training to teach science in primary schools. Environmental Education Research, 10(2), 255-271. doi: 10.1080/13504620242000194211

Goldman, D., Yavetz, B., \& Pe'er, S. (2006). Environmental literacy in teacher training in Israel: Environmental behaviour of new students. The Journal of Environmental Education, 38(1), 3-22. doi: 10.3200/JOEE.38.1.3-22

Goldman, D., Yavetz, B., \& Pe'er, S. (2014). Student teachers' attainment of environmental literacy in relation to their disciplinary major during undergraduate studies. International Journal of Environmental \& Science Education, 9(4), 369-383. doi: 10.12973/ijese.2014.222a

Henze, C. (2000). Sustainability in teacher training courses in a sample of German universities. International Journal of Sustainability in Higher Education, 1(3), 280 289. doi: 10.1108/1467630010378185

Higgins, J. P. T., \& Green, S. (Eds.). (2011). Cochrane handbook for systematic reviews of interventions. Retrieved from http://www.cochrane-handbook.org

Junyent, M. (2012). Educació ambiental: un enfocament metodològic en formació inicial del professorat d'Educació Primària (Doctoral dissertation). Retrieved from http://www.tdx.cat/bitstream/handle/10803/7967/tmjp.pdf?sequence=5

Karpudewan, M., H., Ismail, Z., \& Mohamed, N. (2009). The integration of green chemistry experiments with sustainable development concepts in pre-service teachers' curriculum: Experiences from Malaysia. International Journal of Sustainability in Higher Education, 10(2), 118-135. doi: 10.1108/14676370910945936

Kılınç, A. (2010). Can project-based learning close the gap? Turkish student teachers and proenvironmental behaviours. International Journal of Environmental \& Science Education, 5(4), 495-509. doi: 10.12973/ijese.2014.22

Kyridis, A., Mavrikaki, E., Tsakiridou, H., Daikopoulos, J., \& Zigouri, H. (2005). An analysis of attitudes of pedagogical students towards environmental education in Greece. International Journal of Sustainability in Higher Education, 6(1), 54-64. doi: 10.1108/146763705 10573131

Madhawa Nair, S., Rashid Mohamed, A., \& Marimuthu, N. (2013). Malaysian teacher trainees' practices on science and the relevance of science education for sustainability. International Journal of Sustainability in Higher Education, 14(1), 71-89. doi: 10.1108/14676371311288967

Marcinkowski, T. J., Volk, T., \& Hungerford, H. R. (1990). An environmental education approach to the training of middle level teachers: A prototype programme. Retrieved from http://www.unesco.org/education/information/pdf/333_52.pdf 
Miles, R., Harrison, L., \& Cutter-Mackenzie, A. (2006). Teacher education: A diluted environmental education experience. Australian Journal of Environmental Education, 22(1), 49-59.

Puk, T., \& Stibbards, A. (2010). Ecological concept development of pre-service teacher candidates: Opaque empty shells. International Journal of Environmental \& Science Education, 5(4), 461-476.

Sinha, S., Jangira, N. K., \& Das, S. (1985). Environmental education: Module for preservice training of social science teachers and supervisors for secondary schools. Retrieved from http://kpe-kardits.kar.sch.gr/Aiforia/Unesco/333_14.PDF

Stone, J. M. (1989). Preparing teachers to become involved as environmental educators. Contemporary Education, 60(3), 159-62.

Suárez, J. P., \& Teixé, G. M. (2007). Pasado, presente y futuro de la Educación Ambiental en la formación inicial del profesorado [Past, present and future of environmental education in pre-service teacher training]. Revista Electrónica Interuniversitaria de Formación del Profesorado [Interuniversity Electronic Journal of Teacher Education], 10(1), 1-15.

Summers, M., Childs, A., \& Corney, G. (2005). Education for sustainable development in initial teacher training: Issues for interdisciplinary collaboration. Environmental Education Research, 11(5), 623-647. doi: 10.1080/13504620500169841

Sureda-Negre, J., Oliver-Trobat, M., Catalan-Fernández, A., \& Comas-Forgas, R. (2014). Environmental education for sustainability in the curriculum of primary teacher training in Spain. International Research in Geographical and Environmental Education, 23(4), 281-293. doi: 10.1080/10382046. 2014.946322

Tal, T. (2010). Pre-service teachers' reflections on awareness and knowledge following active learning in environmental education. International Research in Geographical and Environmental Education, 19(4), 263-276. doi: 10.1080/10382046.2010. 519146

Tuncer, G., Boone, J. W., Tuzun, O. Y., \& Oztekin, C. (2014). An evaluation of the environmental literacy of pre-service teachers in Turkey through Rasch analysis. Environmental Education Research, 20(2), 202-227. doi: 10.1080/13504622.2013. 768604

UNESCO (United Nations Educational, Scientific and Cultural Organisation). (1975). The Belgrade Charter. A global framework for environmental education. Retrieved from http://portal.unesco.org/education/en/file_download.php/47f146a292d 047189d9b3ea7651a2b98The+Belgrade+Charter.pdf

UNESCO (United Nations Educational, Scientific and Cultural Organisation). (1977). The Tbilisi Declaration. Retrieved from http:/unesdoc.unesco.org/images/0003/ 000327/032763eo.pdf

UNESCO (United Nations Educational, Scientific and Cultural Organisation). (1987). The Moscow Declaration. Retrieved from http://unesdoc.unesco.org/images/0008/ 000805/080583eo.pdf

UNESCO (United Nations Educational, Scientific and Cultural Organisation). (1990). Environmentally educated teachers: The priority of priorities? Connect, 5(1), 1-3.

UNESCO (United Nations Educational, Scientific and Cultural Organisation). (1997). Declaration of Thessaloniki. Retrieved from http://resources.spaces3.com/f49d 326a-5930-45cf-a9ef-4d23a0670a6d.pdf 
UNESCO (United Nations Educational, Scientific and Cultural Organisation). (1999). UNESCO Chair in Reorienting Teacher Education towards Sustainability. Retrieved from http://www.unesco.org/en/university-twinning-and-networking/access-byregion/europe-and-north-america/canada/unesco-chair-in-reorienting-teachereducation-towards-sustainability-430/

UNESCO (United Nations Educational, Scientific and Cultural Organisation). (2009). Bonn Declaration. Retrieved from http://www.desd.org/ESD2009_BonnDeclaration 080409.pdf

UN (United Nations). (1992). Conference on environment and development. Retrieved from https://sustainabledevelopment.un.org/content/documents/Agenda21.pdf

Van Petegem, P., Blieck, A., \& Pauw, J. B. D. (2007). Evaluating the implementation process of environmental education in pre-service teacher education: Two case studies. The Journal of Environmental Education, 38(2), 47-54. doi: 10.3200/ JOEE.38.1.47-54

Varga, A., Kószó, M. F. Z., Mayer, M., \& Sleurs, W. (2007). Developing teacher competences for education for sustainable development through reflection: The environment and school initiatives approach. Journal of Education for Teaching, 33(2), 241-256. doi: 10.1080/02607470701259564

Wilke, R. J. (1985). Mandating pre-service environmental education teacher training: The Wisconsin experience. The Journal of Environmental Education, 17(1), 1-8.

Wilke, R. J., Peyton, R. B., \& Hungerford, H. R. (1987). Strategies for the training of teachers in environmental education. Retrieved from http://unesdoc.unesco.org/ images/0007/000732/073252E.pdf

Yavetz, B., Goldman, D., \& Pe'er, S. (2014). How do pre-service teachers perceive 'environment' and its relevance to their area of teaching? Environmental Education Research, 20(3), 354-371. doi: 10.1080/13504622.2013.803038

Wong Bing Kwan, F., \& Stimpson, P. (2003). Environmental education in Singapore: A curriculum for the environment of for the national interest? International Research in Geographical and Environmental Education, 12(2), 123-138. doi: 10.1080/ 10382040308667522

Correspondence concerning this paper should be addressed to Olaya Álvarez-García, a PhD candidate, Department of Applied Pedagogy and Pshychology of Education, Balearic Islands University, Carretera Valldemossa Km. 7,5, Building Cifre de Colonya, Palma de Mallorca, Postal Code: 07122, Spain. Email: olaya.alva@gmail.com 